\title{
OVERCOMING THE POVERTY TRAP THROUGH EDUCATION: AN INTERGENERATIONAL STUDY ON INDONESIA
}

\author{
Hilda L Masniarita Pohan* \\ Department of Development Economics, Parahyangan Catholic University \\ Jeffrey D. Vitale \\ Department of Agricultural Economics, Oklahoma State University
}

\begin{abstract}
Poverty has an inter-generational dimension. Individuals born into poor families are constrained to obtain education. Low education leads to low productivity which then leads to low income. The purpose of this study is to present a case study of Indonesia's experience with public expenditures on education and its effect on inter-generational poverty alleviation and medium term impact on individual income. This study uses Indonesian Family Life Survey (IFLS) data consisting of families' income, level of education, and health data over a ten year period. The results suggest that education explains the income variation. Parents' income plays a bigger role in predicting children's income than parents' income. It suggests the importance of education in breaking the inter-generational poverty trap.
\end{abstract}

Keywords: poverty trap, education, income, intergenerational study

JEL Classifications: I24, I32

\section{INTRODUCTION}

Poverty is a problem to societies throughout the world and for many reasons beyond moral and ethical concerns. It does not only constrais people's spending ability but also lowers market potential which makes investment unprofitable (Cheng and Kwan, 2000 and Attanasio and Szèkely, 2004). Poverty has also inter-generational dimension. One who is born into a poor family will be more likely to end up in poverty as well. The relationship is illustrated in figure 1 below.

Rampant poverty has been found to be correlated with relatively low economic growth. According to World Bank (2012), good economic performance are associated with

\footnotetext{
* Corresponding E-mail: mpohan@unpar.ac.id
} 
low poverty rates. In a report that involved almost every country in the world from 1980 to 2012, poverty was found to be a significant factor explaining economic performance. The study found several important outliers that exemplify the importance of poverty in explaining economic performance. In countries such as Hungary, which have been successful in reducing poverty, had $\$ 13,535$ per capita GDP and only 0.2 of its population living below the $\$ 1.25$ poverty line. At the other end of the spectrum, sub Saharan African countries, such as Liberia, which have been plagued by chronic poverty in both rural and urban areas for decades, had a $\$ 213$ GDP per capita with nearly $41 \%$ of its population living below poverty level. This comparison highlights the importance of addressing economic growth.

\section{Figure 1. The Inter-Generational of The Cycle of Poverty}

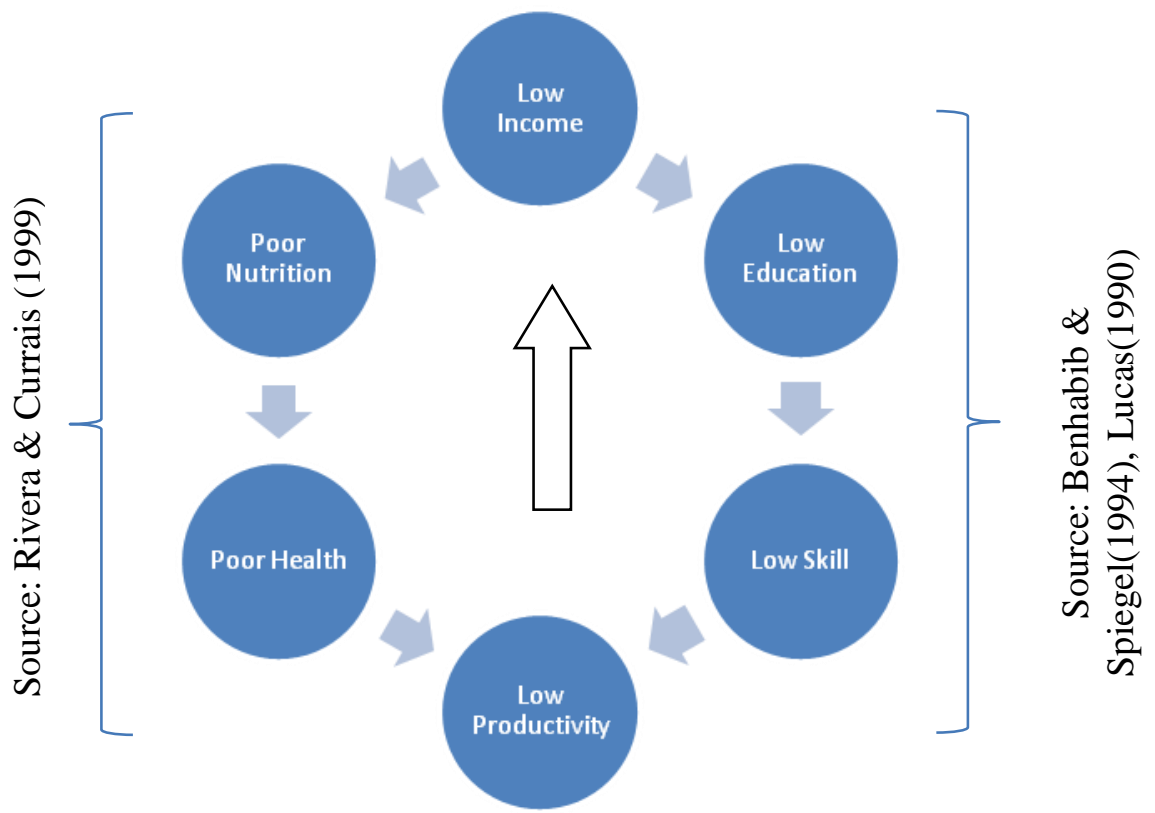

The openness to international market tend also to significantly boost the economics growth. Richards' study (1993) on three Dynamic Asian Economies (Korea, Taiwan, and Thailand), Ponzio's study on Mexico (2005) and Marelli and Signorelli's study (2011) on China and India are a few among many who had studied the positive relationship between countries' trade openness and their economic growth. However, empirical studies 
suggested that trade liberalization or industrialization, when taken individually often widens income inequality (Foster and Rosenzweig, 2003). China's industrialization widened its inter-regional income gap (Yao, 1997). In Mexico, while the rate of Foreign Direct Investment went from $1.4 \%$ to $9.8 \%$ after it joined GATT in 1985, the wage rate gap widened (Feliciano, 2001).

Concentrated wealth means there are only a limited number of people having enough purchasing power. Therefore, it implies that countries with better distributed wealth potentially have stronger market and hence better domestic economic performance. For example: income share held by the highest $10 \%$ of the population was slightly below $30 \%$ in 2000 for the US and for the Netherlands it was $23 \%$ in 1999, while in lower income countries such as Brazil or Colombia, its percentages were $47.7 \%$ in 2001 and $46.1 \%$ in 2002 respectively (World Bank, 2012).

Furthermore, as suggested by figure.1, underprivileged individuals are also more likely to be undereducated and hence are less productive. Consequently, they cannot contribute as much as they should to the economy. Reports from The World Bank (2012) showed that a poor country such as Burkina Faso, with GDP per capita of $\$ 522$, had merely $15 \%$ of its secondary school-aged children enrolled in secondary school in 2012. By contrast, South Korea or Japan which had GDP per capita of $\$ 16,959$ and $\$ 39,473$ respectively had at least $95 \%$ of enrollment.

Equality was actually suggested to be correlated with higher per capita income (Kuznets, 1955). Kakwani et.al (2004) suggested that there is a consensus among development economists that poverty alleviation can only make an impact when accompanied by real income growth and redistribution of income (Oyekale et.al 2011). A research on Nigeria's households from 2003 through 2004 reported that poverty rate declined by 7.85\% during 1998 - 2004. Using Shapley decomposition, it was shown that while growth accounted for $4.38 \%$ increased in poverty rate, redistribution actually accounted for $12.23 \%$ poverty reduction (Oyekale et.al, 2011).

Sylwester's multiple studies reported that public education expenditures were positively associated with a long term growth. Cross sectional study on Sub Saharan Africa, Latin America, and East Asia countries found that an increase in public expenditure in 
education lead to significantly faster growth (Sylwester, 2000). Public education expenditure was also reported to be associated with a decline of income inequality within a country (Sylwester, 2002).

Stiglitz (1996) reported that in the case of the East Asian economies, ensuring universal education simultaneously promoted enhanced levels of labor productivity, increased economic growth, and greater income equality. The findings of Stiglitz (1996) and Sylwester (2000) suggested that higher levels and higher quality of human capital serves two important macroeconomic purposes. It directly increases labor productivity that promotes the of higher income. Indirectly, increasing education improves income distribution which is correlated with economic growth. Higher economic growth in turn helps poverty reduction that perpetuates better economic performance.

As reported by World Bank (2013), Indonesia underwent a significant improvement in education. Secondary school enrollment went from 66\% to 76\% between 2009 and 2012. Tertiary school enrollment went from 24\% to $32 \%$ within the same period. This phenomenon was accompanied by an increase of growth rate from $4.6 \%$ in 2009 to $5.8 \%$ in 2012. Poverty rate also decreased within this time period. During 2009 and 2012, people living below the $\$ 1.25$ poverty line went from $4.1 \%$ to $2.7 \%$ while proportion of people living below $\$ 2$ poverty line went from $16.5 \%$ to $13 \%$.

The purpose of this study is to present a case study of Indonesia's experience with public expenditures on education and its effect on inter-generational poverty alleviation and medium term impact on individual income. Data used in this study is the Indonesian Family Life Survey (IFLS) covering Indonesian families' income, level of education, and school availability observed over a ten year period. This type of data was chosen to show a more micro level interaction of household decision on human capital accumulation and its impact on their future income.

The rest of the article will be organized as follows. The second section provides literature review, the third section lays out the econometric model used, and the fourth section provides analysis of results. The fifth section provides policy implications and the last section provides conclusion. 


\section{LITERATURE REVIEW}

Previous studies found that there are strong relationships between family's characteristics, income, and education. Individuals coming from a less wealthy family will be more constrained to access to education and health facilities. Hence, they will be more likely to end up being in poverty. Additionally, parents' education also affects their assessment on the value of education. More educated parents tend to value education higher than those with lower education.

Solon (1992) used data from Panel Study of Income Dynamics (PSID) to show an intergenerational income relationship between fathers and sons in the US from 1967 to 1971. The PSID results showed that a percentage increase in the father's income is significantly correlated with the increase in the son's income. Using year-to-year measurements, a one percent increase in the father's income will lead to an increase in the son's income by at least $0.25 \%$ for years $1967-1971$. On the two year average, a percentage increase in the father's $1967-1968$ average income will lead to a $0.425 \%$ increase in the son's income.

The probability of an individual entering or exiting poverty depends, among other things, on whether that individual was previously poor (Jenkins, 2000). It was found using data from the British Household Panel Survey, conducted during the period 1991-1996, that the majority of households who were previously poor will remain poor the next period, or be elevated to to the next higher income group. Of those who were poor in 1991, $53.2 \%$ remained poor in 1992. Even after three years, there was still a significant portion, $34.9 \%$ who remained poor.

Lucas' work (1988) contributed significantly to the theories of economic growth. Neoclassical model such as one by Solow relied heavily on the role of capital accumulation in explaining economic growth (Solow, 1956). However, it failed to adequately explain the role of technology in altering economic growth. Lucas defined human capital as the general skill level of individuals. Further, it was suggested that human capital skills can be improved through schooling. Consequently, education was considered as human capital accumulation which was believed as the driving force of technological changes and the 
source for economic development. Translating it into an individual level, the length of schooling is expected to be correlated with higher personal income.

However, low income individuals are often constrained from access to education. A person born into a more resource endowed family, all else equal, has a higher probability for personal skill improvement which provides greater access to higher-paying jobs that normally require higher skills. Development economics recognizes this concept as the vicious cycle of poverty.

Blau (1999) conducted a study on the effect of family income on the cognitive, social, and behavioral development of young children. It was found that the impacts of family income on cognitive scores are positive and statistically significant. An increase in income was estimated to increase: math scores by 0.203 points, reading ability by 0.189 points, vocabulary tests by 0.262 points, and verbal memory by 0.069 points.

Crosnoe et al. (2002) studied the relationship between economic disadvantage, family dynamics, and adolescent enrollment in higher education. It was suggested that economic disadvantage contributes to the low educational attainment since it shapes parents' assessment of the future. The results showed that amongst children from under privileged families, less than half (48.9\%) of young adults were enrolled or had graduated from 2-4 year colleges. The economic disadvantage also significantly predicted later enrollment in higher education by 0.33 and was significant at the $1 \%$ level.

Aside from parents'income, one's education is also affected by other factors such as parent's education. Ganzach (2000) examined interactions between parents' education, cognitive ability and educational expectations in determining children's educational attainment. Data used were obtained from National Longitudinal Survey of Youth on 8,570 Americans who were born between 1957 and 1964. Among others, one purpose of this study is to show that children's educational attainment is a function of parents' expectation which is formed by their educational attainment. The study found that parents' education strongly influences children's educational expectations and attainment (Ganzach, 2000).

Hahs-Vaughn (2004) investigated the impact of parents' education on students in higher education. Students whose parents have attained no more than high school diploma 
were the least likely to aspire to a bachelor's degree and the least likely to be college qualified. First generation students, those whose parents are not college graduates, often do not use their high school years to prepare for college and hence are not as well prepared as others to pursue college education and often attend less prestigious institutions (high school or other institutions). The analysis was broken into three broad categories: prior college enrollment (includes preparation and planning for college), during college enrollment, and after leaving college. Results showed that pre-collegiate traits were a stronger influence for non-first generation students (0.66 compared to 0.42 for first generation students) and on educational outcomes ( 0.75 compared to 0.28 for first generation students).

Other than education, it has also been believed that healthier individuals will be more likely to achieve higher educational attainment. Better health and nutrition are positively associated with gains in schooling in many areas; enrollment at younger ages, less grade repetition, more grades completed, less absenteeism, and better performance on test scores (Behrman, 1996). Table 1 is a summary of socioeconomic variables related to income variability:

Table 1. Summary of Explanatory Variables

\begin{tabular}{|c|l|c|}
\hline Dependent Variables & Explanatory Variables & Expected Sign(s) \\
\hline \multirow{3}{*}{ Income } & - Age & + \\
& $\bullet$ Parents' Income & + \\
& - Education level & + \\
\hline \multirow{3}{*}{ Education level } & - Health Quality & + \\
& - Age & + \\
& Parents' Income & + \\
& Parents' Education & + \\
\hline
\end{tabular}




\section{ECONOMETRIC MODELS}

To investigate the significance of education in addressing the inter-regional dimension of poverty, the estimation will be conducted for two cohorts. The first generation cohort is defined for parents and the second generation for their children. The generational overlap is not perfect since individuals will not completely pass from young child to parent, however the times series portion of the data set is long enough to detect the effect of changes in the explanatory variables. Parents' cohort income is hypothesized to be a function of age, education, and health as a proxy of the level of human capital for a given individual. All socioeconomic characteristics such as education level and health quality for this category will be treated as exogenous variables and are considered as given. Parents' cohort income is represented by the following regression equation:

$$
\begin{gathered}
y_{0 i}=a_{0}+a_{1} \text { Age }_{0 i}+a_{2} \text { Age }_{0 \mathrm{i}}^{2}+\sum_{s=3}^{6} \alpha_{s} \text { Education }_{0 \mathrm{i}}+\sum_{h=7}^{14} a_{h} \text { Healt }_{0 i} \\
+a_{15} \text { DUrban }_{0 \mathrm{i}}+\sum_{r=1}^{2} a_{r} \text { DRegion }_{0 \mathrm{i}}+\varepsilon_{0 i}
\end{gathered}
$$

Following Solon's indexing, $y_{0 i}$ represents income of parents, $A g e_{0 i}$ represents the age of parents, Education $n_{0 i}$ represents the education attainment of parents, and Health $h_{0 i}$ represents health status index of parents. The variable Age is used as a representation of an individual's experience in order to avoid further endogeneity problems (Bedi and Gaston, 1999). Intuitively, older individuals will be more experienced than younger ones.

The year 1997 is treated as the base period. Individuals aged 5-15 in 1997 are categorized as children and are consistently tracked in subsequent periods, 2000 and 2007, to monitor the progress of their education status over time. The resulting data are used to test hypotheses that education has a significant, positive effect on adult income. Moreover, in order to avoid the simultaneity and misspecification problems, individuals in the children cohorts are limited to those who are not earning income.

Furthermore, the inequality of firms' revenue might also contribute to the difference in wage received by workers. Data for firm level revenue across Indonesian regions are 
unavailable; hence the Gross Regional Domestic Product figures are used as an approximation. In order to avoid losing too many degrees of freedom, the fixed effect of regions is used instead of provinces. The term region, however, will not be used as in a geographical sense but economical instead. Jakarta, as the most developed and advanced province in Indonesia, will be used as a base to investigate whether households' income in each province is significantly different from those in Jakarta. Region 1 will be composed of provinces with household income significantly lower than Jakarta, namely North Sumatra, South Kalimantan, and West Nusa Tenggara. Region 2 will be comprised of provinces that have significantly higher household income than Jakarta, namely West Sumatra, Lampung, Jakarta, West Java, Central Java and Makassar. Region 3 is composed of the richer provinces namely South Sumatra, Yogyakarta, East Java and Bali.

The same basic principle is used to estimate children's income as adults in 2007, but the cohort index is changed from zero to one. Parents' income is included in the estimation to investigate whether or not there is a relationship between children's current income and their parents' socioeconomic condition. Due to age range consideration, which is $15-25$, the variable age is not squared for the children's cohort. This consideration is also supported by the scatter plot of income on age in figure 2 .

Figure 2. Scatter Diagram of Personal Income on Age

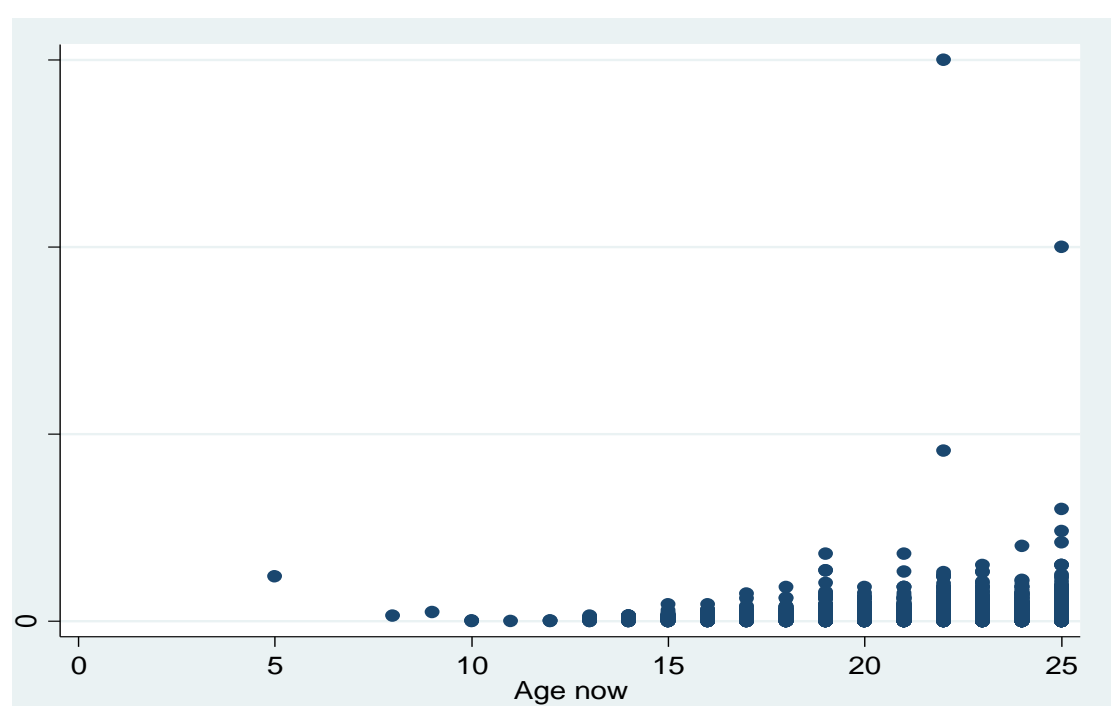

Source: Authors' Calculations 
Specifically, children's income as adults in 2007 is estimated using the following regression equation:

$y_{1 i}=\alpha_{0}+\alpha_{1}$ Age $_{1 i}+\sum_{s=2}^{5} \alpha_{s}$ Education $_{1 i}+\sum_{h=6}^{13} \alpha_{h}$ Health $_{1 i}+\sum_{r=14}^{15} \alpha_{r}$ DRegion $_{1 i}+\alpha_{16} y_{0 i}+\varepsilon_{1 i}$

where Age ${ }_{1}$ represents age of the $i^{\text {th }}$ child in 2007, Education 1 is education level of the $\mathrm{i}^{\text {th }}$ child in 2007, Health 1 is the health quality of the $\mathrm{i}^{\text {th }}$ child in 2007, yoi is income of the $\mathrm{i}^{\text {th }}$ child parent.

Human capital accumulation is an intergenerational process that depends on an individual's relative risk aversion, relative value of physical and human capital, as well as level of output produced. At a family level, it is understood that the optimization process is most likely done by parents, the decision makers in the family. Hence, children's education is estimated as a reduced form function of parents' income, parents' education, and health.

Ordered logit models are used to explain differences in education levels achieved by individuals. Ordered logit models establish relationships between dependent variables measured by an ordinal scale with a set of explanatory variables. While treating them as merely categorical variables and hence employing multinomial logistic regression will not result in a biased estimation, failure to acknowledge the ordinal nature of the variables might lead to an increase of risk of getting insignificant results (Menard, 2002). To further evaluate the impact of development policy through public spending in education, the above model will be expanded to include the availability of schools. As suggested by Dreze and Kingdon (2001), Lavy (1996) and Filmer (2004) education attainment is also a function of school availability. Hence, the education attainment estimation will be represented by the following model, where Distance $_{1 i}$ represents the distance a child must take to get from home to the relevant school.

$$
\begin{aligned}
P\left(\text { Ed }_{1 i}=k\right)= & \alpha_{0}+\alpha_{1} \text { Age }_{1 i}+\alpha_{2} Y_{0 i}+\alpha_{3} Y_{0 i}^{2}+\alpha_{3}{\text { D } \text { Urban }_{1 i}}+\alpha_{4} \text { Health }_{1 i}+\sum_{r=8}^{9} \alpha_{r} \text { Region }_{1 i} \\
& +\alpha_{10} \text { Distance }_{1 i}+\varepsilon_{1 i}
\end{aligned}
$$




\section{RESULT AND ANALYSIS}

\section{Cohort 0 Income Estimation}

The first income estimation is for parents in 1997. For this equation, parents' education and health quality are treated as exogenous variables. The model fit the data reasonably well for a large set of rapid appraisal panel data, with an $\mathrm{R}^{2}$ of 0.248 with five of the nine explanatory variables were found to be significant.

Age variable was one of the most significant significant variables in the model $(\mathrm{P}<0.05$, table 2$)$. The model finds that older individuals will earn higher income, perhaps due to greater experience than younger individuals, and that the negative sign on the quadratic term suggests that the impact of experience on income exhibits diminishing returns.

Table 2. Explanatory Variables of Individual Income Estimation

\begin{tabular}{|l|c|c|}
\hline \multirow{2}{*}{ Variables } & \multicolumn{2}{|c|}{ Coefficients } \\
\cline { 2 - 3 } Age & Cohort 0 in & Cohort 1 in \\
Age Squared & $16.83^{* *}$ & $\mathbf{2 0 0 7}$ \\
Junior High School & $-0.17^{* *}$ & $49.20^{* *}$ \\
High School & $52.80^{* *}$ & - \\
Associate Degree & $292.36^{* *}$ & $168.90^{* *}$ \\
Bachelor's Degree & $480.23^{* *}$ & $349.48^{* *}$ \\
Graduate Degree & $819.21^{* *}$ & $198.87^{* *}$ \\
Health index 2 & $\mathrm{N} / \mathrm{A}$ & $321^{* *}$ \\
Health index 3 & 10.35 & $690.59^{* *}$ \\
Health index 4 & $171.73^{* *}$ & $\mathrm{~N} / \mathrm{A}$ \\
Health index 5 & $135.62^{* *}$ & $199.09^{* *}$ \\
Health index 6 & $176.47^{* *}$ & 146.03 \\
Health index 7 & $155.25^{* *}$ & $321.22^{* *}$ \\
Health index 8 & $148.26^{* *}$ & $288.84^{* *}$ \\
Health index 9 & $204.71^{* *}$ & $448 . .79^{* *}$ \\
Urban setting & $1,222.22$ & $333.84^{* *}$ \\
Region 1 & 13.09 & $\mathrm{~N} / \mathrm{A}$ \\
Region 3 & -4.05 & $231.74^{* *}$ \\
Cohort 0 Income 1997 & $100.89^{* *}$ & -40.54 \\
Cohort 0 Income 2000 & $\mathrm{N} / \mathrm{A}$ & 32.40 \\
\hline & $\mathrm{N} / \mathrm{A}$ & $2.42 \mathrm{e}-5$ \\
\hline
\end{tabular}

Note: $* *=$ significant at $5 \%$

Source: Authors' Calculations 
Higher education had a significant, positive relationship with individual's higher income. On average, individuals with elementary school education or lower would earn \$133.41 annually. A typical individual with Junior High School education is expected to earn $\$ 52.80$ more annually compared to those with Elementary School education. Those with High School education are expected to earn $\$ 292.36$ more annually compared to those with Elementary School education. Those with an Associate Degree and a University degree are expected to earn $\$ 480.23$ and $\$ 819.21$, respectively, more annually compared to those with only Elementary School education.

Almost all of the health quality variables have significant effects $(\mathrm{P}<0.05)$ on individual income. Positive signs indicating healthier individuals included in the data set earned more annually (Table 2). On average individuals with health index of 1 would earn $\$ 221.27$ annually. All things being equal, individuals with better health index would earn at least $\$ 135.62$ more than those with health index 1.

Although provinces in region 2 have higher GRDP than provinces in region 1, most of the provinces in the two regions actually do not have fundamentally different economic characteristics. The majority of the provinces are dominated by agriculture, manufacturing, and small scale service sectors. In contrast, provinces in region 3 are those with predominantly mining and tourism sectors which give higher returns and salary. It can be inferred that individuals living in region 3 are expected to earn $\$ 100.89$ more annually than those living in region 2.

\section{Cohort 1 Income Estimation}

The next estimation is the income estimation in 2007 which only includes individuals who were categorized as non-income earning children in 1997, but now are aged 15-25 years old. The model fit $\left(\mathrm{R}^{2}\right)$ was 0.1544 . Most of the explanatory variables which were significant in explaining parents' income were also significant. Since the age range was shorter, the coefficient for post-secondary education was smaller than the parents' cohort estimation. However, the coefficients of health index for children's cohort were larger than the parents' cohort. 
Age also had a significant effect on Cohort 1 income levels with a larger effect. Among these young adults who are working, their income is positively related with experience and education. The result does not show that those who came from richer families significantly earn more income. An individual who is a year older will earn $\$ 49.20$ more annually and it was statistically significant.

Education has a significant effect on Cohort 1 income levels. Those with Elementary Education earn approximately $\$ 469.50$ annually. A typical individual with Junior High School education is expected to earn $\$ 638.40$. A typical high school graduate is expected to earn $\$ 818.98$. An individual with associate degree education earns $\$ 668.37$ annually. An individual with Bachelor's education or Graduate School education is expected to earn $\$ 790.50$ and $\$ 1,160.09$ respectively.

An interesting point found in the children's cohort estimation is that regional effect failed to have a statistically significant impact on personal income. This is actually a promising result to have in a sense that locational aspect loses its impact vis-a-vis human capital accumulation i.e. education and health. The estimation shows that as individuals get more education and access to health maintenance, their productivity increase and hence receive more income regardless of their location.

Results from this section show that human capital significantly explains individual income. Higher education and better health led to higher income for both parents in 1997 and children in 2007. Furthermore, parents' income does not significantly increase individual's income. In the next section, it will be represented how parents' income impact children human capital.

\section{Indonesian Household Education Estimation}

\section{Cohort 1 Education Attainment in 1997}

On the estimation of cohort 1 education attainment, the initial estimation will be conducted for cohort 1 education attainment in 1997. As a reminder, individuals categorized as cohort 1 are those aged 5-15 in 1997 who are not earning income. The estimation result is presented in table 3.

The model's fit is 0.2900 with eight of fourteen explanatory variables being significant. Older children are more likely to be in higher level of education. The estimation 
result reports an expected sign and is statistically significant. Parents' income has a significant effect on childrens's education level. Parents' income contemporaneously increases the probability of children moving from one education level to the next. This result is expected and is also consistent with the finding of Blau (1999) and Crosnoe et.al (2002).

Since the measurement units for salary in Indonesia is in hundred thousands of Rupiah, the coefficient should be multiplied accordingly. So in this case the relative odds is 1.07 which means it is 1.07 times more likely that a child will go to the next education level due to IDR 100,000 increase in parents' income from the mean value of $\$ 2,310,342$. The significant negative number of the squared term suggests diminishing returns.

Table 3. Explanatory Variables of Cohort 1 Education Attainment

\begin{tabular}{|l|c|c|c|}
\hline \multirow{2}{*}{\multicolumn{1}{|c|}{ Explanatory Variables }} & \multicolumn{3}{c|}{ Coefficients } \\
\cline { 2 - 4 } & Year 1997 & Year2000 & Year 2007 \\
\hline Age & $1.1600^{* *}$ & $0.7122^{* *}$ & $0.1291^{* * *}$ \\
Cohort 0 Income 1997 & $6.71 \mathrm{e}-7^{* *}$ & $2.09 \mathrm{e}-7^{* *}$ & $4.49 \mathrm{e}-7^{* * *}$ \\
Squared of Cohort 0 Income 1997 & $-7.38 \mathrm{e}-15^{* *}$ & $-3.66 \mathrm{e}-15^{* *}$ & $-3.97 \mathrm{e}-14^{* *}$ \\
Cohort 0 Income 2000 & - & $4.86 \mathrm{e}-8^{* *}$ & $1.68 \mathrm{e}-8$ \\
Squared of Cohort 0 Income 2000 & - & $-2.26 \mathrm{e}-15^{* *}$ & $3.74 \mathrm{e}-16^{* *}$ \\
Cohort 0 Income 2007 & - & - & $3.74 \mathrm{e}-8^{* *}$ \\
Square of Cohort 0 Income 2007 & - & - & $-6.82 \mathrm{e}-16$ \\
Health & $1.0373^{* *}$ & $0.0955^{* *}$ & -0.2277 \\
Urban Setting & -0.2473 & $0.4169^{* *}$ & $0.3507^{* *}$ \\
Region 1 & -0.4459 & -0.0527 & 0.1082 \\
Region 3 & $-1.6651^{* *}$ & $0.6160^{* *}$ & 0.1269 \\
Cohort 0 Junior High School & -0.0346 & $0.8329^{* *}$ & $0.4975^{* * *}$ \\
Cohort 0 High School & $2.3863^{* *}$ & $1.0789^{* *}$ & $1.0288^{* * *}$ \\
Cohort 0 Associate Degree & $-1.2764^{* *}$ & $1.0573^{* *}$ & $1.6650^{* * *}$ \\
Cohort 0 Bachelors & $-1.4033^{* *}$ & $1.6701^{* *}$ & $3.0604^{* * *}$ \\
Cohort 0 Grad School & $\mathrm{N} / \mathrm{A}$ & 0.2181 & $4.3047^{* * *}$ \\
Elementary School Distance & 0.0596 & $-0.0544^{* *}$ & -0.0058 \\
Junior High School Distance & -0.0346 & $-0.0064^{* *}$ & $0.0195^{*}$ \\
High School Distance & 0.0213 & $0.0024^{* *}$ & 0.1082 \\
University Distance & - & $0.0145^{* *}$ & 0.1269 \\
\hline & $\mathrm{R}^{2}=0.2900$ & $\mathrm{R}^{2}=0.3519$ & $\mathrm{R}^{2}=0.2160$ \\
\hline
\end{tabular}

Note: ${ }^{* *}$ : significant at $5 \%$

Source: Authors' Calculations 
Health coefficient was 1.0373 and statistically significant. Since $\exp (1.0373)=2.82$, it means that a children with better quality health is 2.82 times more likely to move to the next level of education. This result reports the expected sign and also confirms with the finding of Behrman (1996). Children with high school graduate parents are almost 10 times more likely to move from one level of education to the next compared to those with elementary education parents. Again, this result shows the expected sign, and also in accordance with Ganzach (2000) and Hahs-Vaughn (2004).

\section{Cohort 1 Education Attainment in 2000}

The next estimation is to investigate whether this relationship changes over time. The same estimation is conducted for these individuals in 2000. The model's fit was 0.3519 with sixteen of eighteen explanatory variables are statistically significant.

As reported in column 2 of table 3, older children are more likely to attain higher education level and the coefficient is statistically significant. The relative odds ratio is 2.038. This means that the event of a typical child being in a higher level of education is 2.038 more likely to happen as the child gets older. This result is intuitive and as expected.

Parents' income significantly affects probability of attaining higher level of education. In the year 2000, a small increase in the lagged parents' income (parents' income in 1997) will make the event of a typical child move to a higher level of education 1.03 times more likely to happen. An increase in contemporaneous parents' income (parents' income in 2000 ) is estimated to make the event of a child attaining higher education 1.01 more likely to happen. Coefficients of squared parent income for both contemporaneous and lagged came up negative which suggests diminishing returns. Increase in parents' income will increase the probability of attaining higher education but at a decreasing rate.

Healthier children are found to be more likely to move from one educational level to the next. As the health index gets higher, the event of a particular child moves from one education attainment to the next is 1.1 more likely to happen. Again, it is is as expected and consistent with Behrman's (1996) finding.

On the geographical aspect, children who live in urban areas are found more likely to move from one educational level to the next compared to their rural counterparts. Being in region 3 increased children's relative odds to move to the next educational level by 1.85 . 
Again, this means that a typical child living in region 3 is 1.85 times more likely to have a higher education attainment compared to those living in the base region, namely region 2 .

Parents' education still shows a strong contribution in explaining a child's education level. Having parents who have junior high school education will increase the relative odds ratio of children to be in higher level of education by 2.30. This means that children with Junior High School education parents are 2.3 times more likely to move to the higher level of education compared to those with parents having Elementary School education. Parents who are high school graduate will increase the probability by 2.94 . Children with parents having associate degree education are more likely to achieve a higher education by 2.88 . The children of parents with university degrees are 5.31 times more likely to pursue higher education, and children of parents with graduate degrees are 1.24 times more likely to move from one education to the next.

In relation to the potential impact of public spending, the results show that an additional kilometer of distance to elementary school decreases the probability of a child going to the next level of education. The relative odds is 0.95 which is less than 1 . This means that the event of moving to the next level of education is less likely to take place. An additional kilometer of distance to junior high school decreases the probability of attaining the next level of education to 0.99 . This means that the event of a child move to the next level of education is 0.99 times less likely to happen if the distance increases by one kilometer.

\section{Cohort 1 Education Attainment in 2007}

At the end of the period in which these young adults are tracked, the estimation is again run and the model fit was 0.2160 with almost all explanatory variables being statistically significant. The coefficient of age shows that an older child is 1.13 times more likely to be enrolled in higher education. This finding is consistent with previous estimations.

Parents' income again shows a significant impact in predicting a typical child's education attainment. An increase in the ten-year lagged parents' income predicts a 1.57 addition in the relative odds of an event of a child to move from one education level to the next. An increase in the seven-year lagged parents' income predicts that the event of a child 
being in a higher level of education by 1.18 times. An increase in contemporaneous parents' income makes the event of a typical child to move from one level of education to the next 1.45 times more likely to happen.

Living in urban areas will increase the relative odds of children to be enrolled in higher level education by 1.42. This finding is consistent with what is found in the previous estimation for year 2000. Infrastructures are more likely to be better provided in urban areas than in rural areas. Hence, it makes schools more accessible and opportunity costs of attending schools to be lower.

Children with Junior High School and High School educated parents are 1.64 and 2.80 times more likely to be enrolled in higher education, respectively. The relative odds get bigger as parents' education gets higher as well. Again, this finding is consistent with what suggested by Ganzach (2000) and Hahs-Vaughn (2004). Better educated parents value education higher. It affects their preference and choice with respect to sending their children to school.

Similar to what was found in the year 2000, an additional distance to school for Elementary and Junior High Schools significantly reduces the probability of children moving from one level of education to the next. An additional distance to Elementary School and Junior High School is predicted to make the event of a typical child to move from one education level to the next to be 0.89 and 0.96 times less likely to happen respectively. This is almost in the same tone with what suggested by the urban area indicator variable. Further school means the school is less accessible and consequently makes the opportunity cost of attending school higher.

However, distance to university actually increases the relative odds ratio. An additional distance to university makes the event of a child moving to a higher level of education 1.02 more likely to happen. This is due to the fact that universities and colleges, especially reputable ones, are mostly located at urban areas or in Java Island. Hence, the further away children travel for education; it is most likely to attend post-secondary education.

One important finding of this study is the strong positive role of education in improving household income. Parents' education shows higher coefficients in explaining 
children's educational attainment, suggesting a higher, stronger impact than those of parents' income. Though not necessarily negates the importance of income, this finding gives a hope of overcoming poverty trap through reducing barriers to education. Taking the inter-generational linkage, it can be suggested that making education affordable and accessible is crucial. Highly educated parents value education higher which then explains why they tend to strongly encourage their children to attend school. These higher educated children will then again be more encouraged to send their children to school and maintain the virtuous cycle of improved education. Eventually, it will allow future generations to generate even higher income.

\section{POLICY IMPLICATIONS}

Education remains a central issue in the attempt to increase income. Infusion of human capital is extremely crucial to increase next generation's income and beyond. Assuming no major and abrupt institutional change, this relationship will be a continuous process and make the future generations earn even more money as suggested in figure 3.

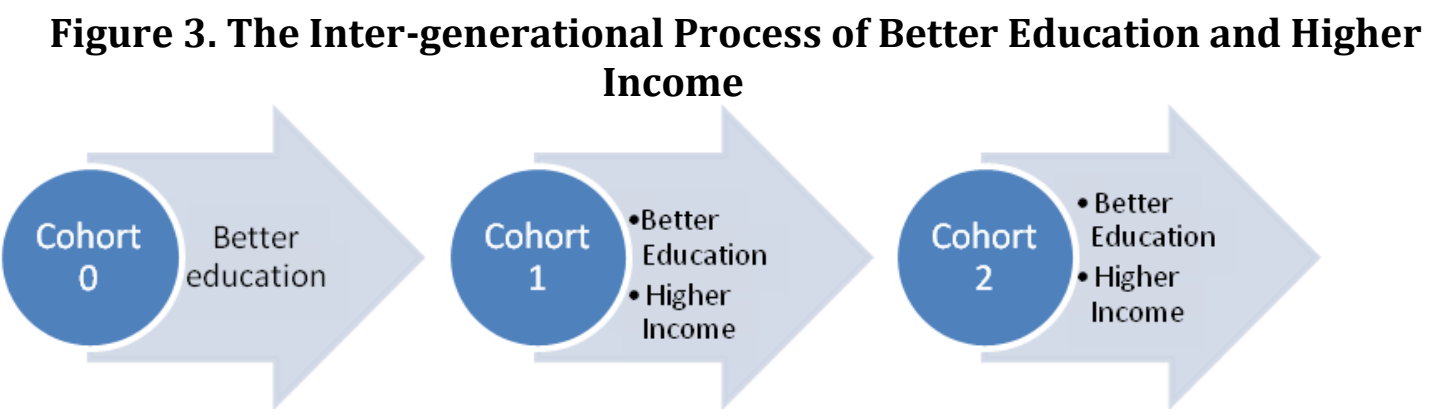

Source: Authors' Illustration

Public spending in order to reduce the opportunity cost of education will allow those who come from less fortunate families to improve their opportunities to catch up to their wealthier counterparts. Though it does not automatically annul the effect of family's wealth in individuals' educational attainment, it diminishes the impact quite significantly. Education should be considered as an integral part of industrialization process. As suggested by Lucas (1988) and Appleton and Balihuta (1996), better human capital helps 
improve technology through better cognitive and non-cognitive skills. The positive externality resulting from public education justifies the disposition of resources to fund public education. The Indonesian data supports this finding as the government increased its share of education spending from $45.3 \%$ in 2009 to $46.8 \%$ in 2012 , intellectual property received went from $\$ 38,128,141$ in 2009 to $\$ 58,049,486$ in 2012 , Additionally, economic growth went from $4.6 \%$ to $5.8 \%$ within the aforementioned time (World Bank, 2013).

One of the advantages of public education provision is that it avoids misallocation of government budget. The potential problem with cash subsidies is that sometimes the money is used to buy goods that are not the main target of the program. For example, food stamp recipients sometimes use the money to buy cigarettes and alcoholic beverages instead of food. If the government spends the money directly on providing schools, teachers, and other educational tools then it can potentially reduce the probability of education money to be spent on goods other than education.

Being the first level of education, availability of elementary school is the most sensitive one to distance. An additional kilometer of elementary school reduces enrollment which substantially decreases probability of attaining higher education. In the case of Indonesia, innately different regional characteristics cause each region to behave differently vis-à-vis an additional distance to a particular level of education. However, it cannot be inferred using this study that there is a need for a "tailor-made" policy for each region.

\section{CONCLUSION}

Contemporaneously, income is explained by education and health. In the absence of government intervention, individuals born in wealthy families will be more likely to attain higher education and also having a better health quality. At the same time, better health also leads to higher education. Moreover, individuals born into more educated families will be more likely to attain higher education. These findings imply that children from wealthier families will end up earning even more money as grownups. It will be a recurring process which feeds on itself and eventually create a larger and larger gap between those with wealth and those without. 
The role of government in providing basic education is extremely important. Making elementary and junior high schools reachable at a convenient distance will increase enrollment in these basic education levels which is a prerequisite to achieve higher educational attainment and ultimately higher income. Higher parents' education helps break the cycle of poverty by allowing children's education to increase so that they earn more than $\$ 2$ per day per person, significantly higher than $\$ 1.25$ per day per person, the poverty level currently designated by World Bank.

\section{REFERENCES}

Appleton, S. M. and Balihuta, A. (1996). Education and Agricultural Productivity: Evidence from Uganda. Journal of International Development, (8), 415-444.

Attanasio, O.P. and Szekely, M. (2004). Wage Shocks and Consumption Variability in Mexico During the 1990s, Journal of Development Economics, Volume 73, Issue 1, p. 1-25.

Bedi, A.S. and Gaston, N. (1999). Using Variation in Schooling Availability to Estimate Educational Returns for Honduras, Economics of Education Review, Volume 18, Issue 1, p. 107-116

Behrman, J. R. (1996). The Impact of Health and Nutrition on Education, The World Bank Research Observer, 11(1), 23-37.

Blau, D. M. (1999). The Effect of Income on Child Development, Review of Economics and Statistics, 81(2), 261-276.

Cheng, L. K. and Kwan, Y. K. (2000). What are the Determinants of The Location of Foreign Direct Investment? The Chinese Experience, Journal of International Economics, Volume 51, Issue 2, p. 379-400

Crosnoe, R., Mistry, R. S. and Elder, G. H. (2002). Economic Disadvantage, Family Dynamics, and Adolescent Enrollment in Higher Education. Journal of Marriage and Family, 64(3), 690-702.

Dreze, J. and Kingdon, G. G. (2001). School Participation in Rural India. Review of Development Economics, 5(1), 1-24.

Feliciano, Z. M. (2001). Workers and Trade Liberalization: The Impact of Trade Reforms in Mexico on Wages and Employment. Industrial \& Labor Relations Review, 55(1), 95115.

Filmer, D. (2004). Determinants of Health and Education Outcomes. Background note for the WDR.

Foster, A. D. and Rosenzweig, M. R. (2003). Economic Growth and the Rise of Forests. The Quarterly Journal of Economics, 601-637. 
Kakwani, N., Khandker, S. and Hyun, H. S. (2004). Pro-Poor Growth: Concepts and Measurements with Country Case Studies.. Working Paper 1. United Nations Development Programme, International Poverty Centre, Brasília.

Kuznets, S. (1955). Economic Growth and Income Inequality. The American Economic Review, 1-28.

Lavy, V. (1996). School Supply Constraints and Children's Educational Outcomes in Rural Ghana. Journal of Development Economics, 51(2), 291-314.

Marelli, E. and Signorelli, M. (2011). China and India: Openness, Trade and Effects on Economic Growth. European Journal of Comparative Economics, 8(1), 129-154.

Menard, S. (Ed.). (2002). Applied Logistic Regression Analysis (Vol. 106). Sage.

Oyekale, A. A., Adeoti, A. I., and Oyekale, T. O. (2011). Income Redistribution, Growth, and Poverty Dynamics During the Period of Economic Reforms in Nigeria, The IUP Journal of Applied Economics, Volume X, No. 2, p. 5-27

Ponzio, C. A. (2005). Globalisation and Economic Growth in the Third World: Some Evidence from Eighteenth-Century Mexico. Journal of Latin American Studies, 37(03), 437-467.

Solon, G. (1992). Intergenerational Income Mobility in The United State, The American Economic Review, Volume 82, Number 3, p. 393-408

Stiglitz, J. E. (1996). Some Lessons from the East Asian Miracle. The World Bank Research Observer, 11(2), 151-177.

Sylwester, K. (2000). Income Inequality, Education Expenditures, and Growth. Journal of Development Economics, 63(2), 379-398.

Yao, S. (1997). Industrialization and Spatial Income Inequality in Rural China, Economics of Transition, 5(1), 97-112. 